So với Youden, sự khác biệt cũng đến từ thời gian phỏng vấn khác nhau, còn nghiên cứu Ty Chow, sự khác biệt do bộ câu hỏi khác biệt tạo sự khác nhau đó[2]. Nhìn chung, sự thiếu sót về kiến thức phần lớn là do sự thiếu các hướng dẫn trong nước về tầm soát vi khuẩn GBS trước sinh, dẫn đến các thực hành cung cấp thông tin khác nhau giữa các bác sĩ, điều này cũng được đồng thuận trong các nghiên cứu trước[1].

Khoảng $42,6 \%$ sản phụ tin rằng thực hiện xét nghiệm tầm soát GBS thường quy cho tất cả sản phụ mang thai là biện pháp tốt để phòng ngừa các bệnh nhiễm trùng do GBS cho trẻ sau sinh. Tỉ lệ này thấp hơn một phần ba so với nghiên cứu ở Ả Râp Saudi (61,8\%)[1] và nghiên cứu ở Hồng Kông (66\%) [2]. Sự khác biệt này có thể là do cách suy nghĩ khác nhau ở các quốc gia khác nhau.

Hạn chế của đề tài: Vì là một nghiên cứu cắt ngang, nên chỉ mô tả hiện tượng của vấn đề nghiên cứu, xác định được các yếu tố liên quan tới kiến thức, thái độ, hành vi về xét nghiệm tầm soát GBS mà không hỗ trợ chúng tôi tìm được mối liên quan nhân quả. Phương pháp lấy mẩu thuận tiện chủ yếu dựa trên sự thuận lợi, dễ tiếp cận đối tượng, phù hợp với nguồn nhân lực và thời gian hạn chế nhưng thường mang tính chủ quan, không thể tính được sai số do chọn mẫu và không thể áp dụng phương pháp ước lượng thống kê để suy rông kết quả trên mẫu cho quần thể chung. Đồng thời, nghiên cứu cũng có thể có sai lệch trí nhớ về các trải nghiệm về xét nghiệm GBS, và sai lệch thông tin khi ghi nhận thông tin thực hiện xét nghiệm GBS của thai phụ trong thai kì dựa trên danh sách thực hiện xét nghiệm tầm soát GBS tại Bệnh viện Từ Dũ mà bỏ qua các cơ sở bên ngoài.

Chúng tôi cũng không tìm hiểu được các nguyên nhân dẫn đến việc đề nghị xét nghiệm tầm soát GBS vẫn còn khá thấp từ các bác sĩ. Mặt khác, nghiên cứu chỉ thực hiện trên các đối tượng chủ yếu khám thai tại bệnh viện Từ Dũ nên sẽ không thể đại diện tất cả sản phụ có tuổi thai từ 36 đến 37 tuần 6 ngày, mặc dù vậy bệnh viện Từ Dũ cũng là bệnh viện sản lớn nhất miền Nam, với hơn hàng nghìn lượt thăm khám mỗi ngày. Tóm lại, kết quả nghiên cứu chưa thể áp dụng cho cộng đồng dân số thành phố Hồ Chí Minh tuy vẫn đạt được một số kết quả dùng để tham khảo.

\section{KẾT LUÂN}

Với nghiên cứu có cõ̃ mẫu 385 chúng tôi thấy rằng tỉ lệ được thông tin về xét nghiệm tầm soát GBS ở thai phụ còn thấp. Từ đó tỉ lệ có được các kiến thức nên về vi khuẩn cũng như xét nghiệm GBS cũng không cao. Mặc dù vậy tỉ lệ thai phụ ủng hộ tầm soát thường qui đối với xét nghiệm này lên tới $42,6 \%$.

\section{TÀI LIÊU THAM KHẢO}

1. Alshengeti A., Alharbi A., Alraddadi S., et al. (2020), "Knowledge, attitude and current practices of pregnant women towards group B streptococcus screening: cross-sectional study, AlMadinah, Saudi Arabia", BMJ Open, 10(2), pp. e032487.

2. Chow Ty, William Wk. (2013), "Knowledge and Attitudes of Hong Kong Pregnant Women on Group B Streptococcus Screening", Hong Kong J Gynaecol Obstet Midwifery 2013, 13, pp. 45-51.

3. Workowski K. A., Berman S., Centers for Disease Control, et al. (2010), "Sexually transmitted diseases treatment guidelines, 2010", MMWR Recomm Rep, 59(RR-12), pp. 1-110.

4. Youden $L_{\text {., }}$ Downing M., Halperin B., et al. (2005), "Group B streptococcal testing during pregnancy: survey of postpartum women and audit of current prenatal screening practices", J Obstet Gynaecol Can, 27(11), pp. 1006-1012.

\title{
THỰC TRANG ĐIỀU TRI THUỐC SINH HỌC Ở BÊNH NHÂN VIÊM KHỚP DẠNG THẤP TẠI KHOA CO' XƯO'NG KHỚP BỆNH VIỆN BẠCH MAI
}

\section{TÓM TẮT}

\author{
${ }^{1}$ Bênh viên đa khoa tỉnh Hà Nam \\ ${ }^{2}$ Đại học Quốc Gia Hà Nội \\ ${ }^{3}$ Bềnh viền Bach Mai \\ Chịu trách nhiệm chính: Lại Hồng Thịnh \\ Email: laihongthinh@gmail.com \\ Ngày nhận bài: 6.8.2021 \\ Ngày phản biên khoa hoc: 6.10 .2021 \\ Ngày duyệt bài: 15.10.2021
}

Lại Hồng Thịnh ${ }^{1}$, Chu Đình Tới ${ }^{2}$, Bùi Hải Bình ${ }^{3}$

Muc tiêu: Mô tả thức trang sử dung thuốc sinh học (bDMARD) trong điều trị viêm khớp dạng thấp (VKDT) tại khoa Cơ Xương Khớp- Bệnh viện Bạch Mai (khoa CXK-BVBM) và xác định một số yếu tố ảnh hưởng. Đối tượng và phương pháp: Nghiên cứu mô tả cắt ngang tiến cứu kết hợp hồi cứu trên 71 bệnh nhân VKDT có dùng bDMARDs tại địa điểm nghiên cứu từ $01 / 2017$ đến 12/2020. Kết quả: bDMARD hay được chọn đâu tiên là thuốc ức chế IL-6 $(83,1 \%)$, có $29,1 \%$ bệnh nhân chuyển sang bDMARD thứ 2 (thường gặp nhất là chuyển sang nhóm ức chế 
TNF), thời gian duy trì thuốc của nhóm ức chế IL-6 là 131 tuần (CI95\%: 108,2-153,8); của nhóm ức chế TNF là 46 tuần (CI95\%: 10,4-81,6), $(p=0,007)$. Tỉ lệ tuân thủ điêuu trị thấp $(29,6 \%)$. Lý do hàng đâu của không tuân thủ điều trị là kinh tế $(35,6 \%)$ và đáp ứng tốt $(31,4 \%)$; của giãn liều là đáp ứng tốt $(62 \%)$ và kinh tế $(24,6 \%)$; của dừng thuốc là do ảnh hưởng của đại dịch Covid-19 $(40,6 \%)$, hết thuốc $(21,7 \%)$ và kinh tể $(20,3 \%)$; và của đổi thuốc là không đáp ứng $(30,3 \%)$, hết thuốc $(36,4 \%)$ vàkinh tế $(27,3 \%)$. Kêt luận: bDMARDs nhóm ức chế IL-6 được lựa chọn để khởi đâu điều trị nhiều nhất và có thời gian duy trì lâu hơn nhóm ức chế TNF. Tí lệ tuân thủ điêu trị thấp và lý do chính của không tuân thủ là không đủ khả năng tài chính. Các yếu tố như không đủ khả năng tài chính, ảnh hưởng của đại dịch Covid-19 và hết thuốc, hoặc không đáp ứng với bDMARDs điều trị là những lý do chính khiến cho bệnh nhân đổi hay dừng thuốc.

Tư khóa: viêm khớp dạng thấp, thuốc sinh học, thực trạng, Bệnh viện Bạch Mai.

\section{SUMMARY \\ CURRENT STATUS OF BIOLOGICAL TREATMENT IN RHEUMATOID ARTHRITIS PATIENT AT THE DEPARTMENT OF \\ RHEUMATOLOGY - BACH MAI HOSPITAL}

Objectives: Describe the current status of using biological drugs in the treatment of rheumatoid arthritis patients at the Department of Rheumatology Bach Mai Hospital and identify some influencing factors. Subjects and methods: A prospective cross-sectional descriptive study combined with a retrospective on 71 rheumatoid arthritis patients receiving biologic drugs at the study site from January 2017 to December 2020. Results: The first-line bDMARD of choice was IL-6 inhibitor (83.1\%), $29.1 \%$ of patients switching to the second biologic drug (the most common being TNF inhibitor), The maintenance time of the IL-6 inhibitor group was 131 weeks (CI95\%: 108,2-153,8), of the TNF inhibitor group was 46 weeks $(C I 95 \%: 10,4-81,6)(p=0.007)$. The rate of adherence was low $(29.6 \%)$. The leading reasons for non-adherence to treatment were economic (35.6\%) and good response $(31.4 \%)$; for dosage reduction were responsive (62\%) and economical (24.6\%); for bDMARD discontinuation were due to the effects of the Covid-19 pandemic $(40.6 \%)$, drug shortage $(21.7 \%)$ and economy $(20.3 \%)$; and for drug switching were non-response $(30.3 \%)$, drug shortage $(36.4 \%)$, and economical (27.3\%). Conclusion: Biologic drugs with IL-6 inhibitors were chosen for the most initiation of treatment and had a longer maintenance time than TNF inhibitors. Adherence rates were low and the main reason for nonadherence was financial incompetence. The main reasons for switching or discontinuing bDMARDs were factors such as financial incompetence, the impact of the Covid-19 pandemic and drug shortages, or nonresponse with bDMARD.

Keywords: Rheumatoid arthritis, biological drugs, reality, Bach Mai Hospital.

\section{I. ĐĂT VẤN ĐỀ}

VKDT là bệnh lý thấp khớp khá thường gặp tại Việt Nam cũng như trên thế giới. Thuốc chống thấp khớp làm thay đổi bệnh (DMARD) có vai trò rất lớn để ngăn ngừa diến tiến của bệnh. Các DMARD gồm hai nhóm là thuốc kinh điển (cSDMARDs) và bDMARDs. Đến nay có chín bDMARDs được chấp thuận trong điều trịVKDT ở châu Âu và ở Mỹ: năm thuốc ức chế TNF (Etanercept, Infliximab, Adalimumab, Certolizumab và Golimumab), một thuốc kháng IL-1 (Anakinra), một thuốc kháng tế bào T (Abatacept), một thuốc kháng tế bào $B$ (Rituximab) và một thuốc ức chế IL-6 (Tocilizumab) ${ }^{1}$.

Hiện nay, bệnh nhân VKDT sử dụng bDMARDs để điều trị ngày nhiều. Tuy nhiên, dùng thuốc càng lâu thì tỉ lệ bệnh nhân dừng thuốc, đổi thuốc cũng tăng dần và việc sử dụng nhóm thuốc này còn bị tác động của nhiều yếu tố như không hiệu quả, tác dụng phụ, kinh tế,....2,3. Muốn tăng cường hiệu quả điêu trị và hiệu quả sử dụngbDMARDs trong điều trị bệnh VKDT thì chúng ta cần phải có các nghiên cứu về tình trạng sử dụngbDMARDs, các nguyên nhân của tình trạng không tuân thủ điều trị, của việc đổi và ngừng bDMARDs.

Ở nước ta hiện nay đã và đang có các nghiên cứu đánh giá về hiệu quả, an toàn và các tác dụng phụ của một số bDMARD sở bệnh nhân VKDT. Tuy nhiên các nghiên cứu về tỉ lệ dùng thuốc, tình trạng điều trị bDMARDs còn ít. Vì vậy chúng tôi tiến hành đề tài này nhằm: mô tả thực trạng sử dụng thuốc sinh học trong điều trị viêm khớp dang thấp tai khoa Cớ Xương Khớp- Bênh viện Bạch Maivà xác định một số yếu tố ảnh hưởng.

\section{II. ĐỐI TƯỢNG VÀ PHƯƠNG PHÁP NGHIÊN CỨU}

1. Đối tượng. Đối tượng nghiên cứu là 71 bệnh nhân VKDT khởi đầuđiều trị bDMARDs tại khoa CXK-BVBM từ01/2017 đến 12/2020 và tiếp tục được theo dõi quá trình điều trị cho đến khi kết thúc nghiên cứu.

Tiêu chuẩn lựa chọn: Bênh nhân có đủ hồ sơ bệnh án từ lần điều trị bDMARD đầu tiên, đồng ý tham gia nghiên cứu và trả lời tất cả câu hỏi trong bệnh án nghiên cứu.

Tiêu chuẩn loai trừ: Bệnh nhân dưới 18 tuổi.

\section{Phương pháp}

Thiết kế nghiên cứu: Nghiên cứu mô tả cắt ngang, lấy số liệu hồi cứu và tiến cứu.

Phương thức chọn mẫu: Lấy mẫu thuận tiện.

Công cụ thu thập dữ liệu: Bệnh án nghiên cứu.

Thời gian thực hiện: Từ 08/2020 đến hết 07/2021.

Địa điểm nghiên cứu: Khoa Cơ xương khớp (với bệnh án tiến cứu) và phòng kế hoạch tổng 
hợp (với bệnh án hồi cứu)- bệnh viện Bạch Mai.

\section{Một số định nghĩa:}

-Đáp ứng tốt/không đáp ứng: Bệnh nhân trả lời là đỡ/khồng đõ khi được hỏi về nguyên nhân không tuân thủ điều trị, nguyên nhân giãn liều, giảm liều, dừng thuốc, đổi thuốc.

-Kinh tế: Bệnh không đủ khả năng kinh tế để tiếp tục dùng bDMARD đúng theo y lệnh

-Tuân thủ điều trị: Lượt tuân thủ điều trị là lượt mà bệnh nhân dùng thuốc theo chỉ định của bác sỹ, bệnh nhân tuân thủ điều trị khi có $\geq 80 \%$ lượt là lượt tuân thủ.

-Lượt giãn liều: Khoảng cách với lượt điều trị trước đó dài hơn khuyến cáo.

-Lượt dừng thuốc: Khoảng cách với lượt điều trị trước đó dài hơn 3 lần khuyến cáo.

-Lượt đổi thuốc: Dùng thuốc khác lượt trước đó và không phải là dừng thuốc.

3. Xử lý số liệu: Chúng tôi sử dụng phần mềm IBM SPSS Statistics 20.0.

\section{KẾT QUẢ NGHIÊN CỨU}

1. Đặc điểm chung của đối tượng nghiên cứu

Bảng 1: Đặc điểm chung của bệnh nhân nghiên cứu

\begin{tabular}{|c|c|c|c|}
\hline \multicolumn{2}{|c|}{ Mức độ hoạt động bệnh (n=71) } & \multicolumn{2}{c|}{ csDMARD(n=71) } \\
\hline Nhè-n (\%) & $4(5,6)$ & Có dùng-n (\%) & $64(91,9)$ \\
\hline Vưa-n (\%) & $39(54,9)$ & Không dùng-n (\%) & $7(9,9)$ \\
\hline Mạnh-n (\%) & $28(39,4)$ & Số thuốc trung bình & $1,44 \pm 0,75$ \\
\hline Corticoid (mg) & $\mathbf{7 , 9 7 \pm 5 , 2}$ & MTX-n/\%/liều (mg/tuần) & $60 / 84,5 / 15,27 \pm 3,54$ \\
\hline Có dùng-n (\%) & $58(81,7)$ & HCQ-n/\%/liều (mg/ngày) & $31 / 43,7 / 200$ \\
\hline \multirow{2}{*}{ Không dùng-n (\%) } & \multirow{2}{*}{$13(18,3)$} & SSA-n/\%/liều (g/ngày) & $7 / 9,9 / 1,29 \pm 0,49$ \\
\cline { 3 - 4 } & & LEF- n/\%/ liêuu (mg/ngày) & $3 / 4,2 / 20$ \\
\hline
\end{tabular}

Bệnh nhân có mức độ hoat động bệnh nhẹ, trung bình và nặng lần lượt là $5,6 \%, 54,9 \%$ và 39,4\%. Trước khi điều trị bDMARD, 91,9\% bệnh nhân có sử dụng CSDMARD và trung bình mỗi bệnh nhân dùng $1,44 \pm 0,75$ thuốc. Tỉ lệ bệnh nhân có dùng methotrexat, thuốc kháng sốt rét tổng hợp, sulfasalazin và leflunomid lần lượt là $84,5 \%), 43,7 \%, \quad 9,9 \%$ và $4,2 \%$. Liều methotrexat trung bình là $15,27 \pm 3,54 \mathrm{mg} /$ tuần và liều thuốc chống sốt rét tổng hợp là $200 \mathrm{mg} / \mathrm{ngày}$ (tính theo HCQ). Có $81,7 \%$ bệnh nhân có sử dụng corticoid trước khi dùng bDMARD với liều trung bình là $7,97 \pm 5,2$ $\mathrm{mg} / \mathrm{ngày}$ tính theo Methylprednisolon (Bảng 1).

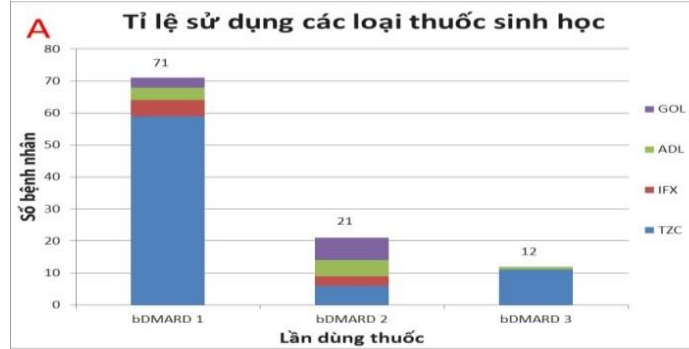

2. Thực trang sử dung bDMARD. Có $83,1 \%$ bểnh nhẩn lựa chon thuốc ức chế IL-6 là thuốc khởi đầu, 16,9\% lựa chọn thuốc ức chế TNF. Có $21(29,6 \%)$ bệnh nhân chuyển sang bDMARDs thứ 2 và 12 bênh nhân chuyển sang thuốc thứ $3(16,6 \%)$. Khi chuyển sang thuốc thứ 2 , nhóm ức chế TNF chiếm 71,4\%, nhóm ức chế IL-6 chiếm $28,6 \%$. Ở bDMARD thứ 3 thuốc ức chế IL-6 chiếm 91,7\% và thuốc ức chế TNF chiếm 8,3\% (Hình $1 A$ ). Thời gian duy trì bDMARD thứ nhất của nhóm ức chế IL-6 là 131 tuần (CI95\%: 108,2-153,8), của nhóm ức chế TNF là 46 tuần (CI95\%: 10,4-81,6), sự khác biệt có ý nghĩa thống kê với $p<0.05$ (Hình 1B).

B

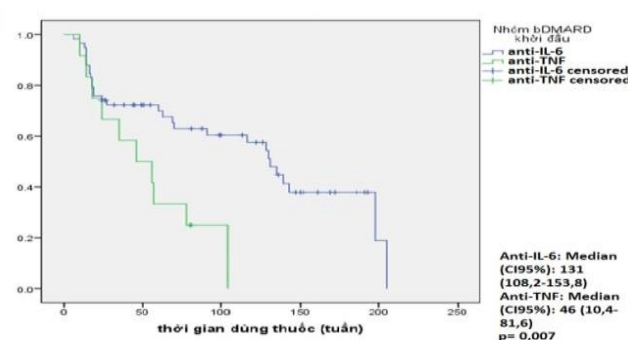

Hình 1: Tỉ lệ và thời gian sử dụng bDMARD

(A): Tỉ lệ sử dụng các thuốc sinh học, $(B):$ Thời gian duy trì thuốc sinh học đâu tiên

Có $83,1 \%$ bệnh nhân lựa chọn thuốc ức chế IL-6 là thuốc khởi đầu, 16,9\% lựa chọn thuốc ức chế TNF. Có $21(29,6 \%)$ bệnh nhân chuyển sangbDMARDs thứ 2 và 12 bệnh nhân chuyển sang thuốc thứ $3(16,6 \%)$. Khi chuyển sang thuốc thứ 2, nhóm ức chế TNF chiếm 71,4\%, nhóm ức chế IL-6 chiếm 28,6\%. Ở bDMARD thứ 3 thuốc ức chế IL-6 chiếm $91,7 \%$ và thuốc ức chế TNF chiếm 8,3\% (Hình 1A). Thời gian duy trì bDMARD thứ nhất của nhóm ức chế IL-6 là 131 tuần (CI95\%:108,2-153,8), của nhóm ức chế TNF là 46 tuần (CI95\%: 10,4-81,6), sự khác biệt 
có ý nghĩa thống kê với $\mathrm{p}<0.05$ (Hình 1B).

Có $21(29,6 \%)$ bệnh nhân tuân thủ điều trị và 50 (70,4\%) bệnh nhân không tuân thủ. Trong tổng số 918 lượt điều trị có $309(33,7 \%)$ lượt không tuân thủ điều trị, $374(40,7 \%)$ lượt giãn liều, $69(7,5 \%)$ lượt dừng thuốc, $33(3,6 \%)$ lượt đổi thuốc (Hình 2A, 2B).

Kinh tế $(35,6 \%)$, đáp ứng tốt $(31,4 \%)$, ảnh hưởng của đại dịch Covid-19 (19,4\%) và hết thuốc $(11 \%)$ là các nguyên nhân chính của việc không tuân thủ điều trị. Các lý do còn lại chiếm 2.6\% (không đáp ứng, tác dụng phụ và các lý do
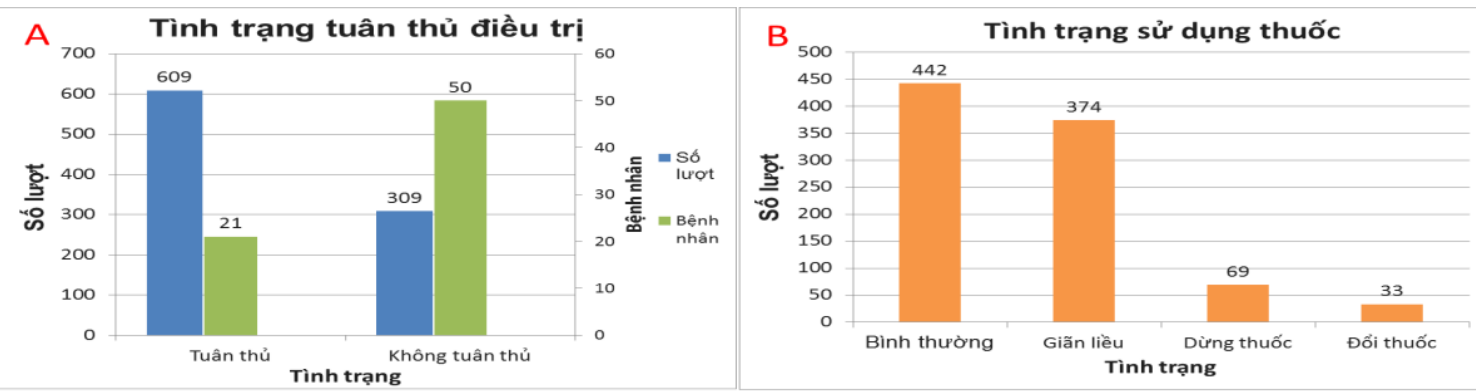

Hình 2: Tình trạng tuân thủ và sử dụng bDMARD

(A): Tỉ lệ tuân thủ điều trị; (B): Tình trạng sử dụng thuốc
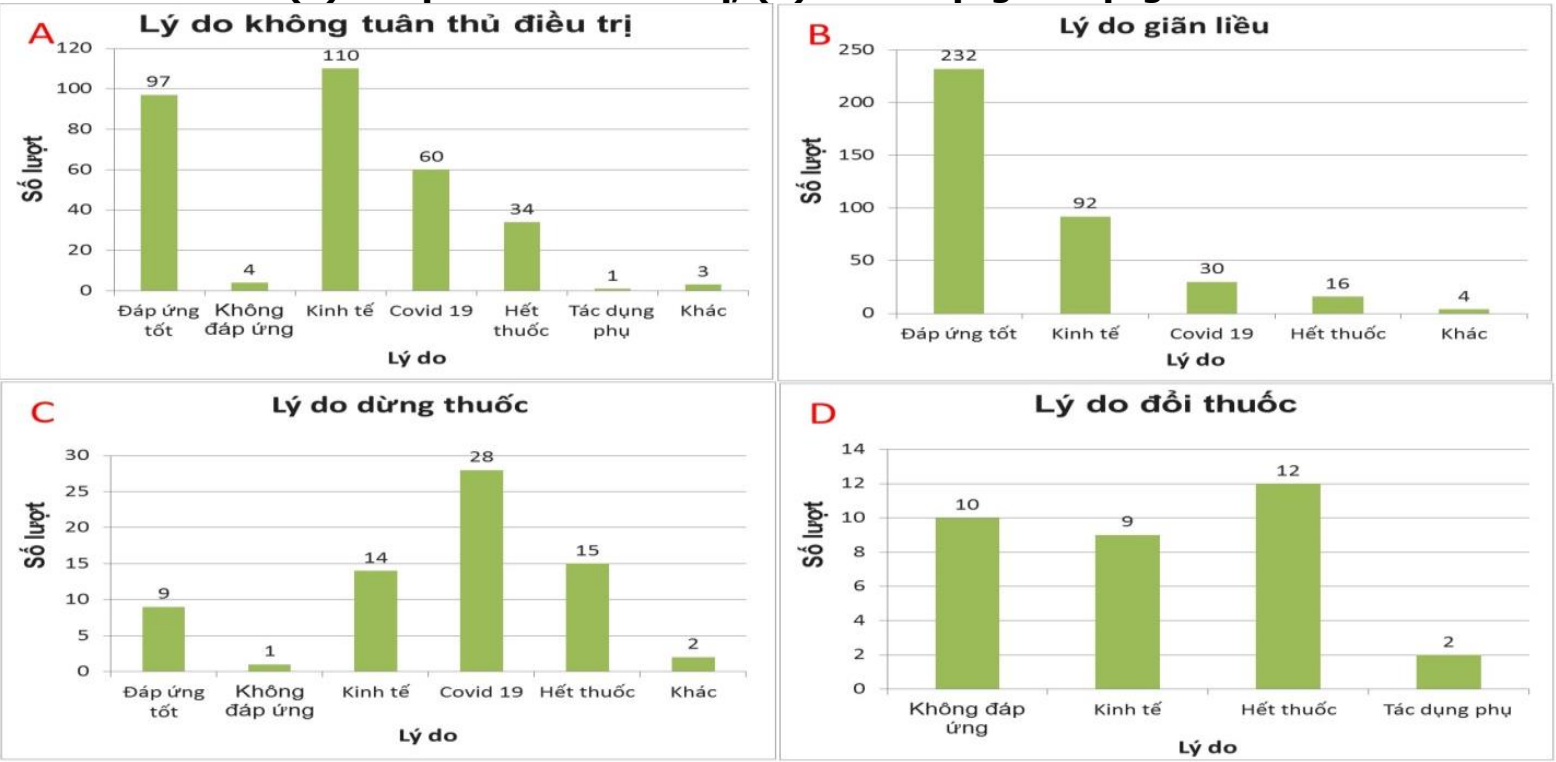

Hình 3: Lý do không tuân thủ điều trị, giãn liều, dừng thuốc và đổi thuốc

(A): Lý do không tuân thủ điều trị; (B): Lý do giãn liêu

(C): Lý do dừng thuốc; (D): Lý do đổi thuốc.

\section{BÀN LUÂN}

Khi bắt đầu được chỉ định dùng bDMARDs để điều trị, phần lớn bệnh nhân có mức độ hoạt động bệnh trung bình và mạnh $(94,4 \%)$, tương tự với nghiên cứu của Emma Sullivan ở cả nhóm bệnh nhân Châu Âu $(94 \%)$ và nhóm bệnh nhân Nhật Bản $(80,8 \%)^{3}$. Phần lớn bệnh nhân có điều trị cSDMARD (91,9\%) và thuốc CSDMARD được lựa chọn nhiều nhất là methotrexat $(84,5 \%)$, tương đồng với các kết quả nghiên cứu của Aaltonen (lần lượt là $86 \%$ và $57 \%)^{4}$ và của Emma Sullivan (nhóm bệnh nhân Châu Âu/Nhật Bản lần lượt là $84,7 \% / 78,6 \%$ và $91,5 \% / 87,3 \%)^{3}$. Điều này chứng tỏ phần lớn các bác sỹ đều tuân 
thủ theo các khuyến cáo điều trị của $A C R$ và EULAR hiện nay, 5 .

Trung bình mỗi bệnh nhân sử dụng 1,44 $\pm 0,75$ thuốc csDMARD, tương tự nghiên cứu của Emma Sullivan ${ }^{3}$ cả cả nhóm bệnh nhân Châu Âu $(1,8 \pm 0,9)$ và Nhật Bản $(1,3 \pm 0,8)$. Điều này thể hiện đa số các bểnh nhân được điều tritưư hai thuốc trở xuốngchứ ít khi kết hợp 3 thuốc CSDMARD, phù hợp với các khuyến cáo điều trị hiện taị ${ }^{5,6}$.

Có $81,7 \%$ bênh nhân có điều tri corticoid với liêu trung bình là $7,97 \pm 5,2 \mathrm{mg} / \mathrm{ngày}$ (tính theo Methylprednisolon) cao hơn so với nghiên cứu của Aaltonen $(69 \% \text { và } 4 \mathrm{mg})^{4}$. Lý do của sự khác biệt này có thểà do corticoid là một thuốc kê đớn nhưng ở nước ta lại có thể mua được khá dễ dàng ở các quây thuốc mà không cần đơn thuốc hợp lệ.

Trong kết quả của chúng tôi,bDMARD hay được lựa chon đầu tiên thuốc ức chế IL-6 $(83,1 \%)$, trong khi theo các kết quả khác thìnhóm ức chế TNF hay được lựa chọn trước như Brodszky $(95,4 \%)^{2}$ và Emma Sullivan $(80,8 \%$ ở nhóm Châu Âu và $64,6 \%$ ở nhóm Nhât Bản) 3 . Điều này có thể do ở nước ta thuốc ức chế IL-6 mà cụ thể là tocilizumab có chi phí sau bảo hiểm y tế cho mỗi tháng thấp hơn nên được ưu tiên lựa chọn trước mặc dù khuyến cáo của EULAR 2019 và $A C R 2021$ không ưu tiên nhóm nào hơn ${ }^{5,6}$.

Có 29,6\% bệnh nhân chuyển sang loai bDMARD thứ 2 và $16,6 \%$ bệnh nhân chuyển sang thuốc thứ 3trong khikết quả của Brodszky hai tỉ lệ này theo thứ tự là $59,6 \%$ và $29,1 \%{ }^{2}$, sự khác biệt này có thể vì nghiên cứu của chúng tôi có thời gian theo dõi ngắn hơn nên tỉ lệ đáp ứng với bMARDs còn cao và bệnh nhân chưa cần đổi thuốc. Khi chuyển sang thuốc thứ 2 thuốc nhóm ức chế TNF chiếm phần lớn $(71,4 \%)$ khác với kết quả của Emma Sullivan (bênh nhân Châu Âu, thuốc ức chế TNF chiếm ít hơn với 47,9\%) thuốc được lưa chon khởi đầu nhiều hơn ở nghiên cứu của chúng tôi và các nghiên cứu khác khác nhau nên khi chuyển sang thuốc thứ hai cũng sẽ có xu hướng ngược nhau, điều này tuân theo các hướng dẩn điều trị hiện có (ưu tiên đổi sang nhóm thuốc khác hơn là đổi thuốc trong cùng một nhóm $)^{5,6}$.

Thời gian duy trì bDMARDs đầu tiên của nhóm ức chế IL-6 dài hơn nhóm ức chế TNF (131 tuần (CI95\%:108,2-153,8) và 46 tuần (CI95\%: 10,4-81,6)), ( $p=0.007)$, tương đương vớikết quả của Brodszky và của Emma Sullivan ${ }^{3}$.

Theo kết quả của chúng tôi thu được, chỉ có 29,6\% (21/71) bệnh nhân tuân thủ điều trị, khác với nghiên cứu của Berger $(80 \%)^{7}$. Điều này có thể vì chúng tôi tiến hành nghiên cứu trong thời gian xảy ra đại dịch Covid-19 và việc bệnh nhân không đủ khả năng tài chính để chi trả cho việc điều trị bDMARDs.

Các lý do gây dừng thuốc gồm ảnh hưởng của đại dịch Covid-19 (40,6\%), hết thuốc $(21,7 \%)$, kinh tế $(20,3 \%)$, đáp ứng tốt $(13 \%)$, không đáp ứng $(1,4 \%)$ và các lý do khác $(2,9 \%)$, trong nghiên cứu của Brodszky, các lý do gây dừng thuốc là không hiệu quả (60\%), tác dụng phụ $(30 \%)$, các lý do khác $(10 \%)^{2}$.Lý do dẫn đến sự khác nhau này có thể là trong thời gian nghiên cứu nước ta có một số thời gian thực hiện giãn cách xã hội, sự khổng sẵn cóbDMARDs ở nước ta cũng như khả năng kinh tế của bệnh nhân.

Các lý do gây đổi thuốc hàng đầu là hết thuốc $(36,4 \%)$, không đáp ứng $(30,3 \%)$,và kinh tế $(27,3 \%)$, có sự khác biệt với các kêt quả của các tác giả khác như Rashid ${ }^{8}$ (không đáp ứng $50,5 \%$, không rõ lý do $25,1 \%$ và tác dụng phụ $22,3 \%$ ), Brodszky ${ }^{2}$ (tác dụng phụ $41 \%$ và không đáp ứng39,6\%). Điều này có thể do sự không sẵn có của bDMARD ởnước ta và khả nắng kinh tế bệnh nhân.

\section{KẾT LUẬN}

Nhóm bDMARD hay được lựa chọn đầu tiên trong điều trị VKDT ở khoa CXK-BVBM là thuốc ức chế IL-6, thời gian duy trì bDMARD đầu tiên của nhóm ức chế IL-6 dài hơn nhóm ức chế TNF. Tỉ lệ tuân thủ điều trị khá thấp so với các nước khác trên thế giới. Lý do hàng đầu của việc không tuân thủ là không đủ khả năng tài chính. Đại dịch Covid-19,hết thuốcvà không đủ khả năng tài chínhlà các lý do chính của việc dừng thuốc. Trong khi các yếu tố chính gây đổi thuốc là không đáp ứng, hết thuốc vàkhông đủ khả năng tài chính. Nghiên cứu của chúng tôi chỉ thực hiện tai khoa CXK-BVBM và trong thời gian ngắn, vì thể cần thực hiện thêm các nghiên cứu tại các cơ sở y tế khác và trong thời gian dài hơn để có được thông tin bao quát hơn về thực trạng sử dụng bDMARD trong điều trị VKDT ở nước ta.

\section{TÀI LIÊU THAM KHẢO}

1. Van Vollenhoven RF. Biologics for the Treatment of Rheumatoid Arthritis. Cham: Springer; 2016.

2. Brodszky V, Biro A, Szekanecz $Z$, et al. Determinants of biological drug survival in rheumatoid arthritis: evidence from a Hungarian rheumatology center over 8 years of retrospective data. Clinicoecon Outcomes Res. 2017;9:139-147.

3. Sullivan E, Kershaw J, Blackburn S, Mahajan P, Boklage SH. Biologic Disease-Modifying Antirheumatic Drug Prescription Patterns Among Rheumatologists in Europe and Japan. Rheumatol Ther. 2020. 
4. Aaltonen KJ, Joensuu JT, Pirila $L$, et al. Drug survival on tumour necrosis factor inhibitors in patients with rheumatoid arthritis in Finland. Scand J Rheumatol. 2016;46(5):359-363.

5. Smolen JS, Landewe RBM, Bijlsma JWJ, et al. EULAR recommendations for the management of rheumatoid arthritis with synthetic and biological disease-modifying antirheumatic drugs: 2019 update. Ann Rheum Dis. 2020;79(6):685-699.

6. Fraenkel L, Bathon JM, England $B R$, et al. 2021 American College of Rheumatology Guideline for the Treatment of Rheumatoid Arthritis. Arthritis Care Res (Hoboken). 2021;73(7):924-939.
7. Berger N, Peter M, DeClercq J, Choi L, Zuckerman AD. Rheumatoid arthritis medication adherence in a health system specialty pharmacy. The American journal of managed care. 2020;26(12):e380-e387.

8. Rashid N, Lin AT, Aranda G, Jr., et al. Rates, factors, reasons, and economic impact associated with switching in rheumatoid arthritis patients newly initiated on biologic disease modifying antirheumatic drugs in an integrated healthcare system. Journal of medical economics. 2016;19(6):568-575.

\section{KẾT QUẢ HÓA TRI PHÁC Đồ CHỨA PLATIN TRONG ĐIỀU TRI UNG THƯ BIỂU MÔ TUYẾN VÚ Có Bộ BA ÂM TÍNH TÁI PHÁT DI CĂN}

\section{TÓM TẮT.}

Mục tiêu: Đánh giá kết quả điều trị bằng phác đồ hóa chất chứa platin trên bệnh nhân ung thư biểu mô tuyến vú có bộ ba âm tính (BBAT) tái phát di căn. Đối tượng và phương pháp nghiên cứu: Nghiên cứu mồ tả hồi cứu trên 56 bệnh nhân được chẩn đoán ung thư biểu mô tuyến vú có BBAT tái phát hoăc di căn. Kết quả: Đặc điểm nhóm nghiên cứu: Tuổi trung bình ở thời điểm tái phát, di căn là $49,2 \pm 12,2$. Thời gian sống thêm không bệnh (DFS) là 16,3 tháng. Trong 56 bệnh nhân điều trị bằng phác đồ chứa platin, có 20 bệnh nhân được điêuu trị bằng phác đồ paclitaxel carboplatin chiểm 35,7\%, 36 bệnh nhân được điều trị bằng phác đồ gemcitabine - carboplatin chiểm 64,3\%. Tỷ lệ đáp ứng chung của phác đồ là $58,9 \%$; trong đó $10,7 \%$ đáp ứng hoàn toàn, đáp ứng 1 phân là 48,2\%, bệnh giữ nguyên là $12,5 \%$, bệnh tiến triển là $28,6 \%$. Tỷ lệ đáp ứng ở nhóm bệnh nhân điều trị phác đồ bước 1 là 67,5\%, cao hơn so với nhóm bệnh nhân điều ở bước 2 là $37,5 \%$, sự khác biệt có ý nghĩa thống kê với $p=0,039$. Trung vị thởi gian sống thêm bệnh không tiến triển là 7 tháng. Độc tính của phác đồ thường gặp chủ yếu là độ 1,2 . Các độc tính thường gặp là hạ bạch câu hạt $(63,5 \%)$, hạ huyết sắc tố $(50 \%)$, hạ tiểu cầu $(26,8 \%)$, rụng tóc $(46,4 \%)$, nôn và buồn nôn $(51,7 \%)$. Kết luấn: Hóa trị phác đồ chứa platin được chứng minh có hiệu quả, độc tính của phác đồ chấp nhận được trên nhóm bệnh nhân UTV BBAT tái phát di căn, do vậy có thể áp dung trong điều trị trong điều kiện hiện nay ở nước ta hiền nay.

Tư khóa: Ung thư vú bộ ba âm tính, platin, thời gian sống thêm bệnh không tiến triển.

\footnotetext{
${ }^{1}$ Trường Đại học Y Hà Nội

²Bênh viên $K$

Chịu trách nhiệm chính: Bùi Thành Lập

Email: lapxuanthu.bhn@gmail.com

Ngày nhận bài: 11.8.2021

Ngày phản biện khoa học: 7.10.2021

Ngày duyệt bài: 15.10.2021
}

\section{SUMMARY \\ THE EFFICACY OF PLATIN-BASE CHEMOTHERAPY OF RECURRENT OR METASTATIC IN THE \\ TRIPLE NEGATIVE BREAST CANCER}

Objectives: To evaluate the efficacy of platinbase chemotherapy of metastatic of triple negative breast cancer. Patients and methods: Retrospective, descriptive study on 56 patients with recurrent or metastatic of triple negative breast cancer, were treated with platin-base chemotherapy regiment at National Cancer Hospital. Results: The mean age was 49,2 $\pm 12,2$. Mean disease-free survival time (DFS) was 16,3 months. The overall response rate (ORR) of the regimen was $58,9 \%$. The complete response rate was $10,7 \%$, the partial response rate was $48,2 \%, 12,5 \%$ of the patients were stable and $28,6 \%$ of the patients had progressive disease. ORR in first-line therapy was better than that in the secondline of treatment (ORR: $67,5 \%$ vs $37,5 \% ; p=0,039$ ). The median progression-free survival was 7,0 months. The common toxicity was neutropenia $(63,5 \%)$, anemia (50\%), 26,8\% for thrombocytopenia, hair loss $(46,4 \%)$, and $51,7 \%$ for vomiting and nausea. Conclusions: Platinum-based chemotherapy is effective in high response rates and progression-free survival for patients with recurrent or metastatic of triple negative breast cancer. However, it is necessary to evaluate and closely monitor the toxicity of the regimen during treatment

Keyword: Triple negative breast cancer, platin, progression-free survival.

\section{I. ĐĂT VẤN ĐỀ}

Theo GLOBOCAN 2020, ung thư vú (UTV) là loại ung thư có tỷ lệ mắc nhiếu nhất trên toàn thế giới và là nguyên nhân gây tử vong thứ 5 sau ung thư phổi, đại trực tràng, gan và dạ dày ở cả 2 giới. Riêng ở nữ giới, UTV chiếm $1 / 4$ số trường hợp ung thư mới mắc và chiếm $1 / 6$ tổng số các ca tử vong do ung thư. Tại Việt Nam, tỷ lệ 